\title{
USING SPACE IN SOCIAL MEDIA TO PROMOTE UNDERGRADUATE STUDENTS' CRITICAL THINKING SKILLS
}

\author{
Fasawang PATTANAPICHET \\ Bangkok University International College \\ Bangkok, Thailand \\ Saovapa WICHADEE \\ Language Institute, Bangkok University \\ Bangkok, Thailand
}

\begin{abstract}
The current study was conducted to see the effectiveness of using social media to enhance students' critical thinking skills. To fulfill the purpose of the study, a 14-week experimental study was performed with two groups of students. Both groups were introduced to how to respond to questions based on Revised Bloom's Taxonomy. During the period of doing the activity, students in the experimental group had to post answers in Facebook and got feedback from peers and teacher as mutual learning while those in the control group wrote their replies in papers and submitted them to the teacher in class. The research instruments used in this study included pre-and post-tests and a questionnaire. The data were analyzed by using dependent t-tests, independent t-tests, means, and standard deviations. After the experiment there was a difference in the mean scores of critical thinking ability between the two groups at the significance level of .05 . The data obtained from the questionnaire manifested students' positive attitudes towards English instruction delivered through questioning technique and postings in Facebook.
\end{abstract}

Keywords: Bloom's Taxonomy, critical thinking, attitude, Facebook, social media

\section{INTRODUCTION}

Critical thinking is defined by Scriven and Paul (2003) as the process to conceptualize, apply, analyze, synthesize, and/or evaluate information collected from observation, experience, feedback, reasoning, or communication, as a way to believe and act. Critical thinkers usually raise vital questions and problems, formulate them clearly, gather and assess relevant information, use abstract ideas, think open-mindedly, and communicate effectively with others. However, passive thinkers who have no ability to analyze and evaluate information tend to have a limited perspective that is thought to be the most sensible one (Duron, Limbach, \& Waugh, 2006). Critical thinking is an important and necessary skill because it is required in the workplace. It can help a person deal with mental and spiritual questions (Hatcher \& Spencer, 2005). It is a skill everyone can develop to improve one's self and others. Since the ability to think critically requires higher-order thinking than simply the ability to recall information, it is necessary for teachers to provide curriculum where critical thinking skills can be reinforced in student learning. 
After a review of literature about critical thinking, I have adopted the Revised Bloom's Taxonomy as a model to use with students in my study. Bloom's Taxonomy was revised by Anderson and Krathwohl (2002) and is a way to categorize the levels of thinking required in classroom situations. There are six levels in the revised taxonomy, each requiring a higher level of abstraction from the students. They comprise remembering, understanding, applying, analyzing, evaluating, and creating. With the strong belief that critical thinking skills can be developed through instruction and practice, teachers attempt to move students up the taxonomy as they progress in their knowledge by incorporating the higher levels into lesson plans and tests. Since the last two levels of the Revised Bloom's Taxonomy (evaluating and creating) are not easy to be achieved, students should be practiced with evaluating external evidence and constructing a theory based on their understanding of the concepts and the relationships between the concepts and empirical evidence regarding the issue of interest (Krathwohl, 2002). The processes of evaluating and creating are often considered "critical thinking," and thus are student outcomes highly desired by most teachers (Krathwohl, 2002). It is necessary for students to realize the characteristics of expected responses so that they will deliberately think and reflect in critical way (Deal \& Hegde, 2013).

Since technology is now playing a significant role in our lives, it is often used as a useful tool to promote critical thinking. According to Nagi and Vate U-Lan (2009), the present societies are the Interaction Age where teamwork, collaboration, and critical thinking that are closely related with virtual learning environments have become enormously vital. Online communication provide deeper critical analysis in student posts than oral discourse in face-to-face settings since students have the time to write, edit, and read others' posts (Maurino, 2006-2007). Due to the constructivist approach which is well suited to the online format (Chang \& Smith, 2008; Legg, Adelman, Mueller, \& Levitt, 2009; Murphy, Mahoney, Chen, Mendoza-Diaz, \& Yang, 2005; Murphy \& RodriguezManzanares, 2009; Payne \& Reinhart, 2008, an individual can interpret the same information differently, so learners can benefit from other responses through shared posts (Ladyshewsky, 2006). In online discussion forum, students can be given feedback and evaluation of postings by other students and teacher. This can be viewed as socialenvironmental influences (Chen, Liu, Shih, Wu, \& Yuan, 2011). Therefore, many educators facilitate online discussions in their courses (Baran \& Correia, 2009; BarnettQueen, Blair, \& Merrick, 2005; Hylton, 2007; Murphy et al., 2005; Thormann, 2008). Discussions can be done in online forums using different technologies such as blogs, forums, and social networking sites. Many previous studies about critical thinking conducted in online forums offered the potential for critical thinking, problem solving, and active group participation (Al-Fadhli \& Khalfan, 2009; Ekahitanond, 2013; Marra, Moore, \& Klimczak, 2004). Moreover, it was found that students had favorable attitudes toward learning using online tools (Ekahitanond, 2013; Kitchakarn, 2012; Kitchakarn, 2013). As such, the current study employed social media as a platform for students to do the activity.

\section{THE USE OF FACEBOOK AS A LEARNING PLATFORM}

In social media, students are able to be more engaged in the learning process as active learners, team builders, collaborators, and discoverers (Ekoc, 2014). Among many types of social media, Facebook is very popular, particularly among the young population who are still studying. There have been reports that as many as 85 to 99 percent of all students are on Facebook (Jones \& Fox, 2009; Matney \& Borland, 2009). Several educational institutions have integrated Facebook into their management, for instance, to promote the institution. Students usually use Facebook as a communication channel when they have an urgent question about the course. Also, they make use of Facebook in their study since this platform makes it possible for them to exchange ideas and opinions with peers and teacher. It is like a stage that gives learners more courage to voice their opinions than in classrooms (Cheung, Chiu \& Lee, 2011). Teachers use Facebook as an 
instructional tool outside of classrooms to connect with the students more quickly. It allows for better participation in the learning activities. Previous studies investigated Facebook use for discussion boards (Estus, 2010; Kent, 2013; Selwyn, 2009; Schroeder \& Greenbowe, 2009). Results from these studies suggested that Facebook in general can contribute positively to higher education. What is more, attitude toward usage of social media in academic platforms has been an important issue. Integrating social media into a course does not only increase student learning achievement, but students also feel satisfied with this online learning. Many studies found that overall students had positive attitudes toward using Facebook in the classroom (Lewis and Nichols, 2012; Mazer, Murphy, \& Simonds, 2009; Munoz \& Towner, 2011; Valenzuela, Park \& Kee, 2009; Li \& Pitts, 2009).

Although Facebook is normally used for discussing general topics, this course takes advantage of it as a platform for students to respond to the questions provided. According to Black (2005), on-line discussions have the potential to motivate student inquiry and create a context in which collaborative learning occurs, promoting both reflection and critical thinking. It will be beneficial if critical thinking ability can be promoted via the social networking tool students were involved with every day like Facebook. Discussions in Facebook gave students a kind of intellectual participation. With this text-based platform, students could initiate their own discussions initiated by the teacher. There were two main objectives of writing in this English course as follows: 1) to improve language use in writing by responding to the questions through the medium of the computer, and 2 ) to encourage critical thinking in the context of online writing.

With the belief that critical thinking skills can be developed well in constructivist learnercentered online learning, the present study integrated the knowledge of levels of thinking of Bloom Taxonomy and Facebook, a popular social networking site, into an arrangement of instruction in order to increase an opportunity to nourish students' critical thinking ability. It aimed to investigate the effects of interaction occurring in Facebook on their critical thinking skills and to explore how students think about the posting activity in Facebook. Although student-to-student interaction create freer discussion and analysis of ideas (Seo, 2007), the present study provided both student-tostudent and student-to-teacher interaction to benefit learning since teachers can help facilitate organization, interpreting, and synthesizing of information and ideas (Wang, 2009). The results in this study will probably produce a useful way of promoting critical thinking.

Three research questions were addressed as follows:

$>$ Research Question 1: To what extent did the students improve their critical thinking ability after they were trained based on the Revised Bloom Taxonomy?

> Research Question 2: Was there any statistically significant difference in the students' critical thinking scores between the two groups after the experiment?

$>$ Research Question 3: How did the students respond to the posting activity in Facebook?

\section{METHODOLOGY}

This study was quasi-experimental research, conducted with second-year students enrolled in EN314 (English for Communication Arts) in first semester of 2014 academic year at Bangkok University. Since students had been already assigned to their sections by the Records Office, it was not possible to randomly select samples out of the population. 
Thus one section was chosen to be a control group while another section was an experimental group. Each group consisted of 40 students from the School of Communication Arts. The reason for choosing students in an advanced course is because higher levels of critical thinking are better introduced in advanced course (Deal \& Hegde, 2013). In this study, the independent variable was the teaching method while the dependent variables were the students' critical thinking ability and their attitude toward the posting activity in Facebook.

This empirical study was carried out in two classes where a native speaker of English was the teacher. The data collection was done for 14 weeks. For the pre-instructional period, the subjects in the two groups were pre-tested to determine their critical thinking ability. Then both groups were taught about how to respond to the questions based on Bloom's Taxonomy in the classroom during week 2 and 3 . Students were taught and practiced on six questioning cognitive levels comprising remembering, understanding, applying, analyzing, evaluating, and creating. The content delivery approach which was employed in this study included the use of advertisement of television clips. These clips can add both entertainment and value to the class. The selection of advertisements as a learning tool in this study was based on the objectives of the course. Advertisements were expected to serve particular needs and interest of the Communication Arts students majoring in Advertising. Apart from authentic languages, slangs, catchy words, moral, and culture they could learn from these ads, the teaching and learning process encouraged students to express their opinions.

Students in the experimental group were required to create a group of ten in Facebook where the teacher would post the questions while they had to give responses to each question. All students had to participate in the writing activity for 5 weeks starting in week 4. In every two weeks (week $5,7,9,11,13$ ), the teacher posted an advertising clip followed by some questions that challenged the students to discuss to achieve the revised Bloom's Taxonomy. Students were required to respond to those questions which had been set to evaluate students' higher-order thinking skills comprising remembering, understanding, applying, analyzing, evaluating, and creating. Each posted question required a response in a well thought-out sentence or paragraph. The response messages were supposed to show how the students could think critically. In this activity, the teacher acted as a facilitator who often read students' writing and gave suggestions about points of view, grammar and mechanics of writing. This provided opportunity for mutual learning and introduced students to new perspectives, which can help them gain more insightful and accurate comprehension (Waterman \& Stanley, 2004). However, students in the control group watched advertising clips and answered the questions individually in a piece of paper in the classroom. The intervention period for both groups took place during weeks 2-13. Then in week 14, two groups were post-tested. After that, only the experimental group rated their attitude towards the posting activity in Facebook on an eight-item questionnaire. The data obtained from the tests and the questionnaire were analyzed quantitatively. To make this activity more motivating, students in both groups would earn 10 points for their participation. As a result, all of them were happy to take part in this activity.

\section{Research Instruments}

The first instrument was the tests administered to assess students' critical thinking ability in both groups. They were created by the researcher. One test was given at the beginning of the term functioning as the pre-test and the second one as the post-test at the end of the experiment. Both tests contained an advertising clip, each of which contained six questions to provoke students' critical thinking based on Revised Bloom's questioning cognitive levels comprising remembering, understanding, applying, analyzing, evaluating, and creating. So, the total score for grading in each test was 30 points. The scoring rubric was used to grade students' answers in a five-level variation as follows: 
$1=$ no relative answer given (no understanding at all)

2 = a very elementary response (no real understanding)

3 = a surface understanding (an average response)

$4=$ a very good understanding and explanation (good description)

$5=$ an excellent description (excellence in understanding and explanation)

The second instrument was a questionnaire examining students' attitude towards the posting activity in Facebook. It consisted of eight items. A Likert five-rating scale (1 = strongly disagree, $2=$ disagree, $3=$ neither agree nor disagree, $4=$ agree, and $5=$ strongly agree) was used for a post-study survey. Students were also encouraged to express their opinion on the posting activity in Facebook in an open-ended form.

\section{Validity and Reliability of the Instruments}

The tests were examined by three teachers of English from the Language Institute to assume language accuracy and content validity. The experts were asked to rate each item so as to see whether it was congruent with the objective. Then, the Item-Objective Congruence (IOC) Index was calculated by assigning scores to three kinds of answers: congruent $=1$, questionable $=0$, incongruent $=-1$. In this study, all items were rated higher than 0.50 of the IOC index, indicating that they were acceptably congruent with the objectives.

Since the clips employed in the two tests were not the same, the three experts justified that the questions along with the clips were not much different in terms of their difficulties. They were also asked to rate whether the questions were under a particular level. The content validity measured by the IOC Index was between $0.66-1.00$. Then, the test was piloted with 35 students enrolled in EN314 who were not the target group. The value of coefficient alpha after piloting with other $\mathbf{4 0}$ students was 0.83 .

The items of the draft questionnaire were written by the researcher and were checked for content validity by the three experts in the English teaching field. The items with IOC index higher than 0.60 were acceptable. In order to test the proper reliability of the questionnaire, the questionnaire was piloted with 35 undergraduate students who were not the target group, and calculated for proper reliability value by using Cronbach's Coefficient Alpha. The Coefficient Alpha of 0.89 indicated that all items were acceptable.

\section{DATA COLLECTION \& ANALYSIS}

To collect data, critical thinking tests were administered before and after exposing students to the treatment. This study employed two raters for marking the papers. Each student's performance was recorded in terms of points. In order to confirm the reliability of test scores, inter-rater approach of reliability estimates was calculated. The correlation coefficients were calculated and the results from the pre-test scores were 0.856 while the correlation coefficients of the post-test scores were 0.924 . The pre- and post-test mean scores in each group were compared by using dependent samples t-tests to reveal changes in performance of critical thinking ability. The mean scores of critical thinking ability of the two groups were compared using an independent samples t-test.

Moreover, an attitude questionnaire, arranged in a five-point Likert scale, was utilized at the end of the experiment for the experimental group. The scores of the questionnaire were calculated by using mean and standard deviation and interpreted in a form of level to indicate how students in the experimental group perceived the use of posting activity in Facebook for language learning. A mean score of 1-1.50 indicates having an attitude at a very negative level, 1.51-2.50 at a negative level, 2.51-3.50 at a moderate level, 3.514.50 at a positive level, and 4.51-5.00 at a very positive level. 


\section{RESULTS}

Research Question 1- To what extent did the students improve their critical thinking ability after they were trained based on the Revised Bloom Taxonomy?

Before the intervention, the mean scores of students in the control and experimental groups were 11.02 and 11.00 , and those scores increased to 18.93 and 21.12 respectively. From a t-test analysis, the post-test mean score of students in the control group was significantly higher than their pre-test mean score $[t(40)=20.85, p=.000]$. This means that the students improved their critical thinking through studying with the traditional way. Likewise, the results indicate that students in the experimental group who were exposed to posting replies in Facebook made a significant improvement $[t(40)$ $=23.34, \mathrm{p}=.000]$ on their critical thinking ability after 14 weeks. Based on such findings, it could be claimed that the English instruction delivered through the integration of critical thinking model and the use of social media, Facebook, was effective in enhancing students' critical thinking.

Table: 1

Comparison of Pre-Test and Post- Test Scores of the Two Groups

\begin{tabular}{lcccccc}
\hline \multirow{2}{*}{ Mean Score } & \multicolumn{2}{c}{ Before } & \multicolumn{2}{c}{ After } & t & \multirow{2}{*}{ Sig } \\
\cline { 2 - 6 } & $\bar{X}$ & S.D. & $\bar{X}$ & S.D. & \\
\hline Control Group $(\mathbf{n = 4 1 )}$ & 11.02 & 4.50 & 18.93 & 4.31 & 20.85 & .000 \\
\hline Experimental Group (n=41) & 11.00 & 3.52 & 21.12 & 3.51 & 23.34 & .000 \\
\hline
\end{tabular}

Research question 2- Was there any statistically significant difference in the students' critical thinking scores between the two groups after the experiment?

To ascertain that the samples assigned to the two groups were not initially different but homogeneous, an independent samples t-test was run to compare the pre-test scores of both groups. The Levene's Test for equality of variances shows $F=1.863$ and $p=.176$, proving that the variance of the groups was equivalent. It was also found that the pretest mean score of students in the control group was nearly equal to that of students in the experimental group $(11.02,11.00)$. The result showed $t=.027$, $d f=.80$, and $p$ $=.978$, indicating that the two groups did not differ significantly, but were homogenous (See Table 2). Therefore, it can be concluded that both groups were homogenous at the outset of the study.

Table: 2

Results of the Levene's Test for Equality of Variances

\begin{tabular}{lccccc}
\hline \multicolumn{1}{c}{ Group } & F & Sig & t & df & Sig \\
\hline Equal Variance assumed Equal & 1.863 & .176 & .027 & 80 & .978 \\
Variance not assumed & & & .027 & 75.609 & .978
\end{tabular}

This research question explored students' critical thinking skills after the intervention. To test the hypothesis and to see the efficacy of the treatment, students' scores obtained from the post-test of the two groups were compared to see if there was a statistically significant difference using an independent samples t-test. The result indicated that the post-test mean score of the experimental group $(M=21.12, S D=3.51)$ was higher than that of the control group $(M=18.93, S D=4.31)$. The results from a $t$-test analysis revealed a difference in the mean scores between the two groups at a significance level 
of $.05(t=2.529, \mathrm{df}=80, p=.013)$, and the variance of the two groups were equivalent ( $F=.735$ and $p=.394)$. So, the null hypothesis stating that no significant difference existed in the mean scores of the students who were controlled to receive the traditional learning environment and those in the experimental group was rejected.

Table: 3

Comparison between Post-test Scores between the Two Groups

\begin{tabular}{lccccc}
\hline \multicolumn{1}{c}{ Group } & X & S.D. & df & t & Sig \\
\hline Control Group $(\mathrm{n}=41)$ & 18.93 & 4.31 & 80 & 2.529 & .013 \\
Experimental Group $(\mathrm{n}=41)$ & 21.12 & 3.51 & & & \\
Mean Difference & 2.19 & & & & \\
\end{tabular}

Research Question 3 - How did the students respond to the posting activity in Facebook? According to Table 4, the overall mean score indicated students' positive attitudes towards the posting activity in Facebook (Mean $=4.17$ ). The three highest scores of the students' attitudes fell on statements no. 8, 7, and 6 respectively. That is, the students had very positive attitudes toward the activity in terms of promoting critical thinking (Mean = 4.85). Moreover, they expressed positive attitudes towards the activity regarding motivation to learn English (Mean $=4.58$, ) and on the increase of interaction with other students (Mean = 4.47). The lowest mean score of the questionnaire was statement no.4 showing that the activity broadened views on various issues at a moderate level $($ Mean $=3.28)$.

Table: 4

Means and standard deviations of student attitudes toward the posting activity in Facebook

\begin{tabular}{lll}
\hline \multicolumn{1}{c}{ Statement } & Mean & S.D. \\
\hline 1. This activity provided relaxing learning environment. & 4.15 & .53 \\
2. This activity helped to promote students' mutual relationship. & 3.55 & .96 \\
3. This activity improved my writing skill. & 4.10 & .50 \\
4. This activity broadened my views on various issues. & 3.28 & .82 \\
5. This activity enabled me to share ideas with teacher and peers. & 4.43 & .50 \\
6. This activity increased interaction with teacher and peers. & 4.47 & .64 \\
7. This activity increased motivation to learn in this course. & 4.58 & .64 \\
8. This activity promoted students to think critically. & 4.85 & .36 \\
\hline \multicolumn{1}{c}{ Total } & 4.17 & .39
\end{tabular}

\section{DISCUSSION AND CONCLUSION}

This study employed setting questions in a social media to provoke communication and critical thinking of undergraduate students. As displayed in Table 3, students in the experimental group outperformed those in the control group, so it could be claimed that critical thinking delivered through the posting activity in Facebook was more effective. Such findings could be explained that the use of social networking site like Facebook and critical thinking model capitalized interaction and active experience, which were theoretically vital to language learning. For instance, the students had opportunities to read different replies to the same question. Unlike individual assignments, posting in Facebook required students to be aware of their peers' contributions. Online 
communication provide deeper critical analysis in student posts than oral discourse in face-to-face settings since students have the time to write, edit, and read others' posts (Maurino, 2006-2007). They had an opportunity to learn to improve thoughts from their peers' answers. In addition, they could interact with both peers and the teacher in English as well as exchange opinions, while learning in class could not provide these circumstances. Therefore, opportunities to interact in social media and actively engage in all the learning steps were abundantly provided, hence enhanced not only students' writing skill, but also their critical thinking skills.

The use of social media like Facebook has a significant role to play in learning. It provides a platform for students to express their thoughts in groups. Collaborative learning occurs through answering questions that could be read by peers. In other words, reading other replies in Facebook broadened their viewpoints. It is like a stage that gives learners more courage to voice their opinions than in classrooms (Cheung, Chiu \& Lee, 2011). Facebook is believed to be an effective tool for mutual learning like Estus (2010) stated that it was easier for students to discuss topics on Facebook. Similar to previous studies which found Facebook to be successfully used for discussion boards (Selwyn, 2009; Schroeder \& Greenbowe, 2009; Estus, 2010). The findings generally lend support to many previous studies about critical thinking conducted in online forums which offered the potential for critical thinking, problem solving, and active group participation (Al-Fadhli \& Khalfan, 2009; Ekahitanond, 2013; Marra, Moore, \& Klimczak, 2004).

The score increase in both groups suggested that students benefited from the instruction of higher thinking. This is probably due to the fact that the students were able to answer the questions more systematically after they were introduced to the critical thinking model. They generated replies that reflected what they had learned, showing connections between their prior knowledge, the course content, and their personal experiences. In this study, the higher thinking levels which were introduced to them enabled them to think more critically and reasonably. This reason can be supported by Ekahitanond (2013) who stated that it is necessary for students to realize the characteristics of expected responses so that they will deliberately think and reflect in critical way. Moreover, answers that were posted by peers could provide students with different perspectives. This activity helped them to develop their replies in a more sensible way. These reasons can be supported by Krathwohl (2002) who states that the processes of evaluating and creating can be provided to improve critical thinking of students. Even though these stages are rather difficult to achieve, the practice makes them gradually improve their critical thinking.

Based on the finding of the questionnaire, the total mean score of the students' responses to questions was 4.17. A high percentage of the students' responses in the attitude questionnaire indicated that most students had favorable attitudes towards the posting activity in Facebook used for language learning. The finding was found to be in accordance with previous studies (Ekahitanond, 2013; Kitchakarn, 2012) which found that students had positive attitudes toward learning with online tools. Their responses to an open-ended part provided at the end of the questionnaires also confirmed these findings. Many students believed that the activity made learning English more interesting and more enjoyable. Furthermore, some students commented that learning through this activity made them feel more confident to apply their language skills, especially to express opinions. In addition, a great number of students stated that they felt the course helped them improve not only their language but also critical thinking skills. They noted, for example, that "after studying this course, I think I have gained improvement both in my English language skills and reasoning." One student said that "I think I learn a lot about giving personal responses because of the higher levels of critical thinking model explained by the teacher." "I am more sensible after I respond to questions in Facebook and get feedback from peers." 
It could be concluded that posting replies to the questions on Facebook pages was an effective way to provoke learners' critical thinking skills. They feel comfortable in joining the activity in Facebook since a large number are using one in their personal lives. The posting activity which has to be done in social media creates an active and engaging learning environment. It is the best way to encourage expressing opinions and thoughts which enable them to develop deeper critical thinking skills. Their positive attitudes towards the posting activity yield further support to the effectiveness of these two techniques. For this reason, academic activities in social media are worth implementing in EFL courses with an aim to enhance critical thinking skills of students.

\section{BIODATA and CONTACT ADDRESS of AUTHORS}

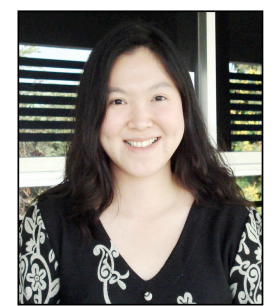

Dr. Fasawang PATTANAPICHET obtained her M.A. in TESOL from Eastern Michigan University, USA and a Ph.D. in English as an international language at Chulalongkorn University. She is now working as a full-time lecturer at Bangkok University International College. Her research interests lie in teaching methodology in EFL. She has many published articles in international journals.

\section{Dr. Fasawang PATTANAPICHET}

Bangkok University International College,

Bangkok, Thailand

Tel: 662-3503500 ext

Email: fasawang.p@bu.ac.th

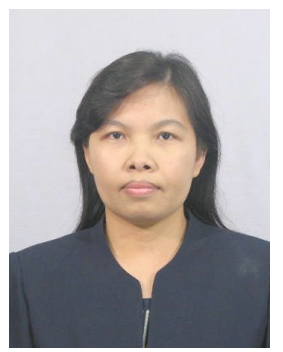

Assoc. Prof. Saovapa WICHADEE received a M.A. degree in English from Srinakharinwirot University, Thailand. She is now working as a fulltime lecturer at Language Institute, Bangkok University, Thailand. Her research interests include teaching methodology in EFL, learners' characteristics, and teacher self-development. Her latest scholarly work focuses on the use of social networks in language teaching. She is a member of the editorial board of The Journal of Asia TEFL (Korea).

Assoc. Prof. Saovapa WICHADEE

Language Institute,

Bangkok University, Thailand

Tel: 662-9020299 ext 2680

Email: saovapa.w@bu.ac.th

\section{REFERENCES}

Al-Fadhli, S., \& Khalfan, A. (2009). Developing critical thinking in e-learning environment: Kuwait University as a case study. Assessment \& Evaluation in Higher Education, 34(5), 529-536.

Anderson, L., \& Krathwohl, D. (2001). A Taxonomy for Learning, Teaching, and Assessing: A Revision of Bloom's Taxonomy of Educational Objectives. New York: Longman. 
Baran, E., \& Correia, A-P. (2009). Student-led facilitation strategies in online discussions. Distance Education, 30(3), 339-361. doi: 10.1080/01587910903236510

Barnett-Queen, T., Blair, R., \& Merrick, M. (2005). Student perspectives on online discussions: Strengths and weaknesses. Journal of Technology in Human Services, 23(3/4), 229-244.

Black, A. (2005). The use of asynchronous discussion: Creating a text of talk. Contemporary Issues in Technology and Teacher Education, 5 (1), 5-24. Retrieved October 3, 2005 from http://www.citejournal.org/vol5/iss1/languagearts/article1.cfm

Chang, S. H., \& Smith, R. A. (2008). Effectiveness of personal interaction in a learnercentered paradigm distance education class based on student satisfaction. Journal of Research on Technology in Education, 40(4), 407-427.

Chen, Y., Liu, E., Shih, R., Wu, C., \& Yuan, S. (2011). Use of peer feedback to enhance elementary students' writing through blogging. British Journal of Educational Technology, 42(1), E1-E4.

Cheung, C. M., Chiu, P., \& Lee, M. (2011). Online social networks: Why do students use Facebook? Computers in Human Behavior, 27, 1337-1343.

Deal, J., \& Hegde, S. (2013). Seinfeld and economics: How to achieve the revised Bloom's Taxonomy in an introductory economics class. International Journal of Teaching and Learning in Higher Education, 25(3), 388-395.

Duron, R., Limbach, B., \& Waugh. W. (2006). Critical thinking framework for any discipline. International journal of Teaching and Learning in Higher Education, 17(2), 160-166.

Ekahitanond, V. (2013). Promoting undergraduate students' critical thinking skills through peer feedback activity in an online discussion forum. Alberta journal of Educational Research, 59(2), 247-265.

Ekoc, A. (2014). Facebook groups as a supporting tool for language classrooms. Turkish Online Journal of Distance Education, 15(3), 18-26.

Estus, E. (2010). Using facebook within a geriatric pharmacotherapy course. American Journal of Pharmaceutical Education 74(8):145.

Hatcher, D. L., \& Spencer, L. A. (2005). Reasoning and Writing: From Critical Thinking to Composition. 3rd. ed. Boston: American Press.

Hylton, M. E. (2007). Facilitating online learning communities: A comparison of two discussion facilitation techniques. Journal of Technology in Human Services, 25(4), 6378.

Jones, S., \& Fox, S. (2009). Generations Online in 2009. Retrieved April 14, 2011 from http://www.pewinternet.org/w/media//Files/Reports/2009/PIP_Generations_2009. pdf 
Kent, M. (2013). Changing the conversation: Facebook as a venue for online class discussion in higher education. MERLOT Journal of Online Learning and Teaching. 9(4), 546-565.

Kitchakarn, 0. (2012). Using blogs to improve students' summary writing abilities. Turkish Online Journal of distance Education. 13(4), 209-219.

Kitchakarn, 0. (2013). Peer feedback through blogs: An effective tool for improving students' writing abilities. Turkish Online Journal of distance Education. 14(3), 152-164. Krathwohl, D. R. (2002). A revision of Bloom's taxonomy: An overview. Theory into Practice, 41(4), 212-218.

Ladyshewsky, R. K. (2006). Peer coaching: A constructivist methodology for enhancing critical thinking in postgraduate business education. Higher Education Research \& Development, 25(1), 67-84.

Legg, T. J, Adelman, D., Mueller, D., \& Levitt, C. (2009). Constructivist strategies in online distance education in nursing. Journal of Nursing Education, 48(2), 64-84.

Lewis, B. K., \& Nichols, C. (2012). Social media and strategic communication: A two-year study of attitudes and perceptions about social media among college students. Public Relations Journal, 6(4), 1-10. Retrieved from http://www.prsa.org/Intelligence/PRJournal/Documents/2012LewisNichols.pdf

Li, L. \& Pitts, J. P. (2009). Does it really matter? Using virtual office hours to enhance student-faculty interaction. Journal of Information Systems Education, 20(1), 175-185.

Marra, R. M., Moore, J. L., \& Klimczak, A. K. (2004). Content analysis of online discussion forums: A comparative analysis of Protocols. Educational Technology Research \& Development, 52(2), 23-40.

Matney, M., \& Borland, K. (2009). Facebook, blogs, tweets: How staff and units can use social networking to enhance student learning. Paper presented at the annual meeting of the National Association for Student Personnel Administrators, Seattle, WA, USA, March 12, 2009.

Maurino, P. S. M. (2006-2007). Looking for critical thinking in online threaded discussions. Journal of Educational Technology Systems, 35(3), 241-260.

Mazer, J. P., Murphy, R. E., \& Simonds, C. J. (2009), The effects of teacher self-disclosure via Facebook on teacher credibility. Learning, Media and Technology, 34(2), 175-183.

Muñoz, C. L., \& Towner, T. (2011). Back to the "wall": How to use Facebook in the college classroom. First Monday, 16, 12-15.

Murphy, K. L, Mahoney, S. E., Chen, C-Y, Mendoza-Diaz, N. V., \& Yang, X. (2005). A constructivist model of mentoring, coaching, and facilitating online discussions. Distance Education, 26(3), 341-366.

Murphy, E., \& Rodriguez-Manzanares, M. A. (2009). Sage without a stage: Expanding the object of teaching in a web-based, high-school classroom. International Review of Research in Open and Distance Learning, 10(3), 1-19. 
Nagi, K., \& Vate-U-Lan, P. (2009). Using emergent technologies for facilitating engaged learning in a virtual learning environment. International Journal of the Computer, the Internet and Management, 17(1), 61-66.

Payne, C. R., \& Reinhart, C. J. (2008). Can we talk? Course management software and the construction of knowledge. On the Horizon, 16(1), 34-43.

Schroeder, J., \& Greenbowe, T. J. (2009). The chemistry of Facebook: Using social networking to create an online community for the organic chemistry. Innovate: Journal of Online Education, 5(4), 1-7.

Scriven, M., \& Paul, R. (2003). Defining Critical Thinking. Retrieved October 8, 2011, from http://www.criticalthinking.org/University/univclass/Defi ning.html

Selwyn, N. (2009). Faceworking: Exploring students' education-related use of Facebook. Learning, Media and Technology, 34, 157-174.

Seo, K. K. (2007). Utilizing peer moderating in online discussions: Addressing the controversy between teacher moderation and nonmoderation. The American Journal of Distance Education, 21(1), 21-36.

Thormann, J. (2008). Student moderators in an online courses. Online Classroom, 1, 7.

Valenzuela, S., Park, N., \& Kee, K. F. (2009). Is there social capital in a social network site?: Facebook use and college students' life satisfaction, trust, and participation. Journal of Computer-Mediated Communication, 14, 875-901.

Wang, Q. (2009). Design and evaluation of a collaborative learning environment. Computers \& Education, 53, 1138-1146. 